\title{
REVIEW \\ Genomic insights into adaptation to high-altitude environments
}

\author{
ZA Cheviron $^{1}$ and RT Brumfield ${ }^{2}$
}

Elucidating the molecular genetic basis of adaptive traits is a central goal of evolutionary genetics. The cold, hypoxic conditions of high-altitude habitats impose severe metabolic demands on endothermic vertebrates, and understanding how high-altitude endotherms cope with the combined effects of hypoxia and cold can provide important insights into the process of adaptive evolution. The physiological responses to high-altitude stress have been the subject of over a century of research, and recent advances in genomic technologies have opened up exciting opportunities to explore the molecular genetic basis of adaptive physiological traits. Here, we review recent literature on the use of genomic approaches to study adaptation to high-altitude hypoxia in terrestrial vertebrates, and explore opportunities provided by newly developed technologies to address unanswered questions in high-altitude adaptation at a genomic scale.

Heredity (2012) 108, 354-361; doi:10.1038/hdy.2011.85; published online 21 September 2011

Keywords: ecological genomics; functional genomics; hemoglobin; hypoxia; next-generation sequencing; RNA-seq

\section{INTRODUCTION}

The combined effects of hypoxia and cold in high-altitude habitats impose severe physiological challenges on endothermic animals. The decrease in the partial pressure of oxygen $\left(\mathrm{P}_{\mathrm{O} 2}\right)$ at high elevation reduces the oxygen supply arriving at the cells of respiring tissues. This reduction in tissue oxygenation can severely limit aerobic metabolism and constrain thermogenic capacity, which is important to offset the other primary stressor associated with high altitude- the reduction in ambient temperature. Understanding how high-altitude endotherms cope with the combined effects of hypoxia and cold can provide important insights into the process of adaptive evolution, particularly the mechanisms that underlie tradeoffs associated with simultaneous adaptation to co-varying environmental factors.

Altitudinal variation in physiological traits has been documented for many species, and physiological acclimation and acclimatization responses to hypoxia and cold exposure are relatively well understood in endothermic vertebrates. An understanding of the molecular genetic basis of this variation, however, has lagged behind, particularly in natural populations of non-model species. Much of what is known about the genetic basis of high-altitude adaptation in natural populations comes from studies that have taken a 'candidate gene' approach, and many of these studies have focused on sequence variation in hemoglobin genes. Several of these have become well-known case studies of the genetics of adaptation (Snyder, 1978, 1985; Snyder et al., 1982, 1988; Chappell and Snyder, 1984; Jessen et al., 1991; Weber et al., 2002; Storz et al., 2007, 2009, 2010a), but many other physiological traits may be as important as blood oxygen affinity in determining lifetime reproductive success in high-altitude environments. These physiological parameters are often complex traits with a polygenic basis.
Recent advances in high-throughput sequencing technologies make it feasible to extend candidate gene analyses of high-altitude adaptation to analyses of genomic patterns of genetic variation among populations and species that occupy different altitudinal environments (Yi et al., 2010). Similarly, an explosion of genomic data has led to the proliferation of genomic tools, such as complementary DNA (cDNA) and oligonucleotide microarrays, and these tools are beginning to be used to study transcriptomic variation between high- and lowaltitude populations of non-model species (Cheviron et al., 2008). The genomic perspective provided by these technologies promises to yield novel insights into the mechanisms of high-altitude adaptation and acclimatization.

Here we review recent literature on the use of genomic approaches to study the molecular genetic basis of adaptation to high-altitude hypoxia in terrestrial vertebrates. This is not intended to be a review of the physiological mechanisms of high-altitude adaptation, as this topic has been reviewed extensively elsewhere (see, for example, Moore and Regensteiner, 1983; Bouverot, 1985; Monge and Leon-Velarde, 1991; Hochachka, 1998; Moore et al., 1998; Beall, 2003; Scott and Milsom, 2006; Beall, 2007; Storz et al., 2010b), but we do draw on this body of work to make inferences about the adaptive significance of physiological variation in nature, and to identify candidate genes and biochemical pathways that may underlie physiological adaptations.

\section{GENOMIC APPROACHES TO THE STUDY OF HIGH-ALTITUDE ADAPTATION}

Although hypothesis-driven studies of candidate genes have clearly made important contributions to our understanding of the mechanisms of high-altitude adaptation, this strategy has two major limitations: (1) it is unlikely to lead to the discovery of novel adaptive

\footnotetext{
${ }^{1}$ School of Biological Sciences, University of Nebraska, Lincoln, NE, USA and ${ }^{2}$ Museum of Natural Science and Department of Biological Sciences, Louisiana State University, Lincoln, NE, USA

Correspondence: Dr ZA Cheviron, School of Biological Sciences, University of Nebraska, 348 Manter Hall, Lincoln, NE 68588, USA.

E-mail: zcheviron2@unl.edu
}

Received 25 March 2010; revised 3 June 2011; accepted 14 June 2011; published online 21 September 2011 
mechanisms because it relies on $a$ priori understanding of potentially adaptive phenotypes (Storz and Wheat, 2010; Storz and Cheviron, 2011), and (2) the evolution of complex physiological systems that underlie adaptation to high-altitude stress generally require coordinated evolution of many interacting genes (Flowers et al., 2007; Wagner, 2009). Because of the limited genomic scope of many candidate gene approaches, it is often possible to overlook functionally important variation at interacting loci. Discovery-driven approaches that examine patterns of polymorphism at a genomic scale are unconstrained by the current understanding of adaptive phenotypes and as a result are more likely to implicate novel genes and biochemical pathways that participate in high-altitude adaptation. Similarly, because of the scale of genomic approaches, researchers are able to examine hundreds of genes that interact within pathways, allowing them to rapidly expand candidate gene studies to candidate pathway analyses. There are a number of genomic approaches that promise to provide novel insights into the genetic basis of adaptive traits at high altitude.

\section{Genome scans: detecting selection without knowledge of an adaptive phenotype}

The action of positive natural selection leaves characteristic signatures in DNA polymorphism data (Neilsen, 2005). In the case of adaptation to high-altitude environments, positive selection may be expected to elevate levels of differentiation between high- and low-altitude populations and reduce within-population diversity at adaptive (and linked) loci compared with a genome-wide average (Lewontin and Krakauer, 1973; Begun and Aquadro, 1993, 1995; Hudson and Kaplan, 1995; Beaumont and Nichols, 1996; Neilsen, 2001, 2005; Beaumont and Balding, 2004; Beaumont, 2005; Storz, 2005). Similarly, genetic hitchhiking effects will increase the size of local haplotype blocks, and hence the degree of local linkage disequilibrium around loci that contribute to adaptation to different altitudinal zones (Maynard-Smith and Haigh, 1974; Stephan et al., 1992, 2006; Charlesworth et al., 1997; Charlesworth, 1998; Kaplan et al., 1998; Fay and Wu, 2000; Kim and Stephan, 2002; Sabeti et al., 2002; Kim and Nielsen, 2004; Neilsen, 2005; Innan, 2006; Jessen et al., 2007; McVean, 2007; Storz and Kelly, 2008). By surveying genome-wide patterns of DNA polymorphism, it is possible to identify loci that exhibit these characteristic signatures. However, cautious interpretations of genome scan results are necessary because population genetic structure and certain patterns of historical demography can increase the detection of false positives (Andolfatto and Prezeworski, 2000; Teshima et al., 2006; Novembre and Di Rienzo, 2009). Thus, genome scans are best suited for the identification of novel candidate genes, which should be the targets of focused studies to establish the functional significance of this putatively adaptive variation (Storz and Wheat, 2010).

A series of recent genome scans in Tibetans have independently identified genes that participate in the hypoxia-inducible factor (HIF) oxygen-signaling pathway as targets of strong positive selection at high altitude. Tibetans differ from acclimatized lowlanders and other highaltitude human populations by maintaining sea-level hemoglobin ( $\mathrm{Hb}$ ) concentrations at elevations up to $4000 \mathrm{~m}$ (Beall et al., 1998; Beall, 2007). Although moderate increases in hematocrit and $\mathrm{Hb}$ concentration can improve aerobic capacity in normoxia (Ekblom and Hermansen, 1968; Kanstrup and Ekblom, 1984; Ekblom and Bergland, 1991), at high altitude, increased $\mathrm{Hb}$ concentration caused by excessive erythrocytosis can hinder tissue oxygenation by increasing blood viscosity and vascular resistance (Guyton and Richardson, 1961; Connes et al., 2006; Storz et al., 2010b). Correspondingly, theoretical studies have suggested that optimal $\mathrm{Hb}$ concentrations may be near the typical sea-level value (Villafuerte et al., 2004).

Among the many transcriptional responses to hypoxia that are regulated by transcription factors in the HIF-signaling pathway is the control of erythropoiesis (Wang et al., 1995; Rankin et al., 2007), and several HIF-pathway genes have been shown to exhibit both signatures of recent positive selection and an association with $\mathrm{Hb}$ concentration in Tibetans. Among these genes are the egl 9 homolog 1 (EGLN1), endothelial PAS domain 1 (EPAS1 also known as HIF2 $\alpha$ ) and peroxisome proliferator-activated receptor- $\alpha$ (PPARA) genes (Beall et al., 2010; Bigham et al., 2010; Simonson et al., 2010; Yi et al., 2010). EGLN1 degrades HIF $2 \alpha$ proteins under normoxia, preventing the transcription of HIF-inducible genes such as erythropoietin (EPO), which in turn is responsible for increased red blood cell production (Rankin et al., 2007; Simonson et al., 2010) (Figure 1). EPAS1 encodes the oxygen-sensitive $\alpha$-subunit of the transcription factor HIF2, and because of the transcriptional effects of HIF2 on EPO (Figure 1), may also mechanistically contribute to the blunted erythropoietic response in Tibetans. Finally, PPARA expression is inhibited by HIF1 transcription factors under hypoxic conditions, and increased PPARA activity is also known to reduce $\mathrm{Hb}$ concentration (Wilding et al., 2007). For all three of these loci, the allelic variants that are

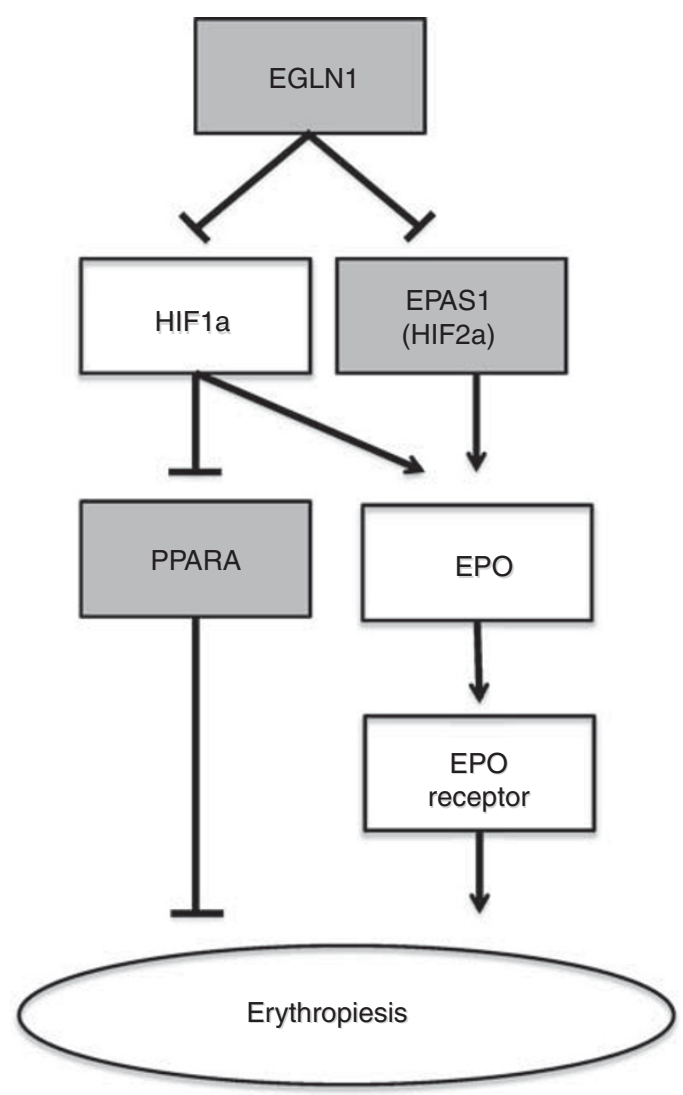

Figure 1 Schematic representation of HIF regulation of erythropoiesis. Gray boxes represent genome scan-nominated candidate genes that have been hypothesized to contribute to the blunted erythropoietic response in Tibetans. The genes in the white boxes are provided for reference. Note that for simplicity, many other genes that participate in erythropoiesis (for example, hepcidin, ferroportin, transferrin and Janus kinase) have been omitted. Figure modified from those in Semenza (2009) and Simonson et al. (2010). 
most common in Tibetans are negatively associated with $\mathrm{Hb}$ concentration (Beall et al., 2010; Simonson et al., 2010; Yi et al., 2010), suggesting that the blunted erythropoietic response in Tibetans may be because of the independent or joint effects of mutations in these genes.

Although these studies utilized different genotyping platforms, analytical methods and independent population samples, all three converged on the HIF pathway as the target of natural selection in Tibetan adaptation to high altitude. Given the pleiotropic effects of the HIF-signaling cascade, however, it is unclear whether $\mathrm{Hb}$ concentration is the direct phenotypic target of natural selection or whether it simply represents a pleiotropic phenotypic effect of selection on another physiological trait that is regulated by the HIF-signaling cascade (Storz, 2010; Storz and Cheviron, 2011). Indeed, EGLN1 was also identified as an outlier in genome scans of high-altitude Andeans (Quechua and Amayra), who exhibit a vigorous erythropoietic response to hypobaric hypoxia (Bigham et al., 2009, 2010), and variation in both EGLN1 and EPAS1 has been implicated in susceptibility to high-altitude pulmonary edema, suggesting another potential phenotypic target of selection (Lorenzo et al., 2009; Aggarwal et al., 2010).

Similar genome scans in indigenous Andean highlanders (Quechua and Amayra) suggest little overlap in the genetic targets of selection in Tibetans and Andeans despite their common evolutionary exposure to high-altitude hypoxia (Bigham et al., 2009, 2010). One striking exception to this pattern is EGLN1, which exhibits signatures of positive selection in both populations (Bigham et al., 2009, 2010; Simonson et al., 2010; Yi et al., 2010). Beyond EGLN1, the apparent genetic targets of selection are different in the two populations. Two loci, PRKAA1 (protein kinase, AMP-activated $\alpha 1$ catalytic subunit) and NOS2A (nitric oxide synthase 2A), exhibit strong signatures of recent positive selection in Andeans, but not in Tibetans (Bigham et al., 2010). PRKAA1 is a cellular ATP sensor that also has effects on HIF-1 transcriptional activity (Jaakkola et al., 2001; Shaw, 2006; Bigham et al., 2010). NOS2A contributes to nitric oxide synthesis that plays important roles in smooth muscle relaxation, vasodilation and increased uteroplacental blood flow (Julian et al., 2009), highlighting the importance of vascular traits as additional phenotypic targets of selection at high altitude (Julian et al., 2009; Bigham et al., 2010). Although some of the apparent differences in the genetic architecture of high-altitude adaptation in Tibetans and Andeans may be attributable to technical and analytical differences among independent studies, as Yi et al. (2010) suggest: 'it is also consistent with the physiological differences between Tibetan and Andean populations (Beall, 2007); suggesting that these populations have taken largely distinct evolutionary paths in altitude adaptation'.

In contrast to other genome scan studies of high-altitude adaptation in humans, Yi et al. (2010) used exon capture arrays to sequence exonic and flanking sequence of nearly 20000 genes, allowing the researchers to determine whether single-nucleotide polymorphisms bearing the strongest signatures of natural selection in Tibetans occur in the coding or regulatory regions of candidate genes. The EPAS1 single-nucleotide polymorphism with the greatest difference in allele frequency between Tibetans and Han Chinese was intronic, and no amino-acid-altering variants had a population frequency difference of $>6 \%$. Similarly, the EGLN1-associated single-nucleotide polymorphism with the greatest allele frequency difference occurs downstream of the EGLN1 coding region. Thus, in both cases, the strongest signal of selection occurred in noncoding regions that may affect gene regulation. PPARA was not detected as an outlier by Yi et al. (2010). Detailed molecular studies are warranted to examine the differences in EPAS1 and EGLN1 gene expression between Tibetans and other highland and lowland populations.

\section{Genome-wide gene expression profiles: detecting variation in gene regulation}

Gene expression profiles are important molecular phenotypes that not only highlight genes that are important in coping with physiological challenges, but also provide insight into the role of regulatory variation in adaptive evolution (Somero, 2005; Gracey et al., 2008). Evidence of the action of positive selection on HIF-transcription factors in humans underscores the importance of gene regulation at high altitude, and experimental exposure to cold and hypoxia are known to have profound effects on genome-wide patterns of gene expression (Gracey et al., 2001, 2004; Powell, 2003; Chen et al., 2005; Fan et al., 2005; Whitehead and Crawford, 2006; Baze et al., 2010). Thus, adaptation to high-altitude habitats may often proceed through mutations that alter gene expression phenotypes.

There are a number of technologies available for measuring genome-wide patterns of gene expression (Lorkowski and Cullen, 2006). The most commonly employed are cDNA and oligonucleotide microarrays. Microarrays are powerful tools for studying genomewide patterns of gene regulation, but they are limited by several technical constraints. Expression level is indirectly inferred from fluorescence intensity, which can be subject to errors associated with differences in hybridization efficiency across probes and biological targets (Lorkowski and Cullen, 2006; Bar-Or et al., 2007). Expression microarrays also suffer by not providing sequence information on mRNA transcripts. Whole transcriptome shotgun sequencing (WTSS or RNA-seq) using next-generation sequencing technologies allows for a direct estimate of relative transcript abundance by sequencing cDNA pools. RNA-seq approaches have a number of advantages over microarrays because they are not reliant on hybridization dynamics, and they allow for the measurement of both transcript abundance and allelic variation among transcripts. These advantages are likely to propel RNA-seq technologies into the forefront of gene expression analysis. However, interpretation of the results of RNA-seq experiments does rely heavily on efficient and accurate mapping of sequence reads to a reference genome, which is subject to nontrivial technical and biological challenges (reviewed in Marguerat and Bähler, 2009; Wang et al., 2009). Regardless of the method employed, analyses of differential gene expression among taxa from different elevational zones are likely to provide novel insight into the role of transcriptional regulation in high-altitude adaptation and acclimatization.

Recently, we used a zebra finch cDNA microarray to measure transcriptomic variation among rufous-collared sparrow (Zonotrichia capensis) populations distributed along an altitudinal gradient in the Peruvian Andes (Cheviron et al., 2008). Initially, we measured gene expression profiles in individuals that were sampled at their native elevations, and identified over 200 genes that were differentially expressed between high-altitude $(4100 \mathrm{~m})$ and low-altitude $(2000 \mathrm{~m})$ populations. Gene ontology and pathway analyses revealed that most of these differentially expressed genes directly interact with one another in oxidative phosphorylation (OXPHOS) and oxidative stress response pathways, suggesting large-scale upregulation of aerobic metabolic processes at high elevation.

To determine the extent to which these gene expression differences were environmentally induced, we also performed a transplant experiment in which individuals were transferred from their native altitude to a common garden at sea level and allowed to acclimate for 1 week before sampling. Under common garden conditions, none of the genes that were differentially expressed at the native altitudes remained 
significantly different, demonstrating dramatic and rapid plasticity in the transcriptomic profiles of $Z$. capensis, and suggesting that the observed expression differences at native elevations were largely environmentally induced. On the whole, the results of these analyses demonstrated that much of the altitudinal variation in metabolic gene expression in $Z$. capensis is because of environmentally induced changes, and not to mutations that permanently affect gene regulation.

These results underscore the importance of experimental design for inference of regulatory adaptation. Because gene expression profiles are inherently plastic, steps must be taken to account for the environmental component of expression differences through either common garden or reciprocal transplant designs. After regulatory variation has been decomposed into environmental and genetic components, it should then be possible to distinguish between regulatory changes associated with physiological acclimatization and evolutionary adaptation.

\section{Pathway population genomics: expanding candidate genes to candidate pathways}

Given that high-altitude adaptation requires coordinated changes in the expression and structure of many genes that participate in interacting biochemical pathways, a holistic understanding of the mechanisms of adaptive evolution at high altitude requires a pathway-level perspective. By expanding the genomic scope from candidate genes to candidate pathways, it is possible to examine the importance of gene interactions in high-altitude adaptation, and to study the genetics of adaptation in integrated biochemical systems. Similarly, because these analyses operate in a hypothesis-driven framework, the design of functional experiments to test the biochemical consequences of genetic variation will be more tractable. A pathwaylevel population genomic approach to the study of high-altitude adaptation is also well suited to make contributions that extend beyond high-altitude research to general questions regarding the genetics of adaptation. For example, how does the network position of genes influence their evolutionary rate? Are genes that occur in upstream pathway positions more likely to contribute to adaptation than those that occur in peripheral positions? Do pleiotropic effects constrain or promote the role of highly connected genes in the process of adaptive divergence? These questions are of fundamental importance to the study of the genetics of adaptation (Cork and Purugganan, 2004), and high-altitude adaptation is a promising system to address them because the molecular pathways that contribute to this process are relatively well characterized.

This type of pathway-level population genomic approach has recently become feasible for most species that occur at high elevations. Again, high-throughput sequencing technologies hold the key for these advances. Sequence-capture arrays are a microarray-based approach for selecting a subset of the genome for efficient resequencing of selected targets (Hodges et al., 2007; Okou et al., 2007; Ng et al., 2009). Custom sequence-capture arrays are available from several commercial suppliers and can be used to capture up to $30 \mathrm{Mbp}$ of target sequence, more than enough to capture all of the $\sim 75$ genes that interact in the mammalian HIF-signaling cascade (Semenza, 2009). Once targets are captured for representative highand low-altitude populations, they can be sequenced rapidly using any high-throughput sequencing technology. Similarly, RNA-seq technologies can be used to sequence the transcriptome of highly metabolic tissues, such as cardiac or skeletal muscle, and comparisons of RNA-seq reads between high- and low-altitude populations can be made in a pathway-population genomic context. This latter strategy is particularly promising because it can also be used to examine transcript abundance. Both of these methods can be applied to virtually any species, and when they are applied to well-characterized pathways, it should be possible to design biochemical assays to test the functional consequences of putatively adaptive variation and make mechanistic connections between genotype and adaptive biochemical phenotypes. Although this pathway-level population genomic approach has not yet been applied to the study of high-altitude adaptation, we anticipate that it will make important contributions to high-altitude research in the years to come.

\section{Integrating genomic and functional data: linking genomic and mechanistic biology}

The best prospects for elucidating the molecular genetic basis of adaptive traits lie in the integration of evolutionary genetic analyses with functional assays (Storz and Wheat, 2010), and a number of studies of high-altitude adaptation have successfully achieved this level of integration. Below we review two recent and exemplary case studies of integration of genetic and functional data to illustrate examples of functional assays that can be used to validate population genomic inferences of adaptive differentiation.

\section{$\mathrm{Hb}$ polymorphisms in deer mice}

In vertebrates, $\mathrm{Hb}$ transports oxygen from the respiratory surfaces, through the blood to the cells of respiring tissues. Changes in oxygenbinding affinity of $\mathrm{Hb}$ proteins can have major effects on oxygen transport, especially under hypoxic conditions, and the increased $\mathrm{Hb}$ oxygen affinity of high-altitude animals is arguably the most famous adaptation to high altitude (reviewed in Perutz, 1983; Bouverot, 1985; Hochachka and Somero, 2002; Weber, 2007; Storz and Moriyama, 2008). Hb oxygen affinity is the product of the intrinsic ability of $\mathrm{Hb}$ molecules to bind oxygen and other erythrocytic cofactors, and the intracellular concentration of these cofactors (Weber et al., 2002; Weber and Fago, 2004; Weber, 2007; Storz and Moriyama, 2008). A number of erythrocytic compounds are known to influence $\mathrm{Hb}$ oxygen affinity in vertebrates. In mammals, an increase in 2,3-diphosphoglycerate (DPG; also known as 2,3-biphosphoglycerate (2,3 $\mathrm{BPG})$ ) and $\mathrm{Cl}^{-}$ions decreases $\mathrm{Hb}$ oxygen affinity by stabilizing the low-affinity deoxygenated conformation of $\mathrm{Hb}$ (Weber, 2007). Inositolpentaphosphate is known to affect $\mathrm{Hb}$ oxygen affinity through similar mechanisms in birds (Lutz, 1980).

The most comprehensive studies of adaptive $\mathrm{Hb}$ differentiation in natural populations have been performed on the deer mouse (Peromyscus maniculatus), which occurs from below sea level in Death Valley, California, to over $4300 \mathrm{~m}$ above sea level in the mountains of western North America (Hall, 1981). In P. maniculatus, two tandemly duplicated genes encode the $\alpha$-chain (HBA-T1 and HBA-T2) and $\beta$-chain (HBB-T1 and HBB-T2) subunits of the tetrameric adult $\mathrm{Hb}$ (Snyder, 1978; Storz et al., 2007, 2009, 2010a). Altitudinal patterns of nucleotide diversity and linkage disequilibrium are indicative of local adaptation of $\alpha$ - and $\beta$-globin genes to different altitudinal zones, and $\mathrm{Hb}$ genotypes differ in oxygen affinity and aerobic performance (measured by $\mathrm{VO}_{2}$ max) (Chappell and Snyder, 1984; Chappell et al., 1988; Snyder et al., 1988; Storz et al., 2007, 2010a, 2009; Storz and Kelly, 2008). The rank order of performance depends on the altitude at which the genotypes are tested, and is also consistent with local adaptation, with high-altitude $\alpha$-globin genotypes outperforming low-altitude genotypes at $3800 \mathrm{~m}$ and vice versa at $340 \mathrm{~m}$ (Chappell and Snyder, 1984; Chappell et al., 1988). Measurements of $\mathrm{O}_{2}$-equilibrium curves demonstrate that the difference in oxygen-binding affinity between high- and low-altitude $\mathrm{Hb}$ genotypes is attributable to reduced binding affinity of allosteric cofactors 
(2,3-DPG and $\mathrm{Cl}^{-}$ions) of high-altitude Hbs (Figure 2) (Storz et al., 2009, 2010a). Moreover, comparisons between Hbs with identical $\alpha$-globin chains but different $\beta$-globin chains suggest that the reduced sensitivity to allosteric cofactors was largely because of variation in the $\beta$-chain (Storz et al., 2009, 2010a). The two main $\beta$-globin allele classes differ from one another by four tightly linked amino-acid substitutions in the $\mathrm{E}$ - and $\mathrm{H}$-helices of the $\beta$-chain subunit, and hence the adaptive differentiation of deer mouse $\mathrm{Hb}$ appears to be attributable to the independent or joint effects of these substitutions.

\section{Cytochrome $c$ oxidase in bar-headed geese}

OXPHOS and ATP production are ultimate end points of oxygen transport. Thus, OXPHOS is a physiological system with obvious functional importance at high altitude. Given its role in the OXPHOS pathway, the mitochondrial genome has recently received renewed attention as a candidate locus for high-altitude adaptation.

The vertebrate mitochondrial genome contains 13 protein-coding genes, all of which play central roles in the OXPHOS pathway. Thermogenic capacity and nonshivering thermogenesis have been shown to be associated with mitochondrial variation between highand low-elevation populations of white-toothed shrews (Crocidura russula), suggesting local adaptation of mitochondrial haplotypes (Fontanillas et al., 2005). Similarly, patterns of population genetic structure and levels of gene flow in rufous-collared sparrows that are distributed along elevational gradients in the Andes also suggest local adaptation of mitochondrial haplotypes (Cheviron and Brumfield, 2009), and patterns of nucleotide substitutions across the mitochondrial genome are suggestive of divergent selection acting on highand low-altitude haplotypes in Tibetan horses, pikas, yaks and several species of high-altitude sheep and goats (Di Rocco et al., 2006; Xu et al., 2007; da Fonseca et al., 2008; Luo et al., 2008; Hassanin et al., 2009).

The bar-headed goose (Anser indicus) has figured prominently in the study of high-altitude adaptation. This species breeds on the high

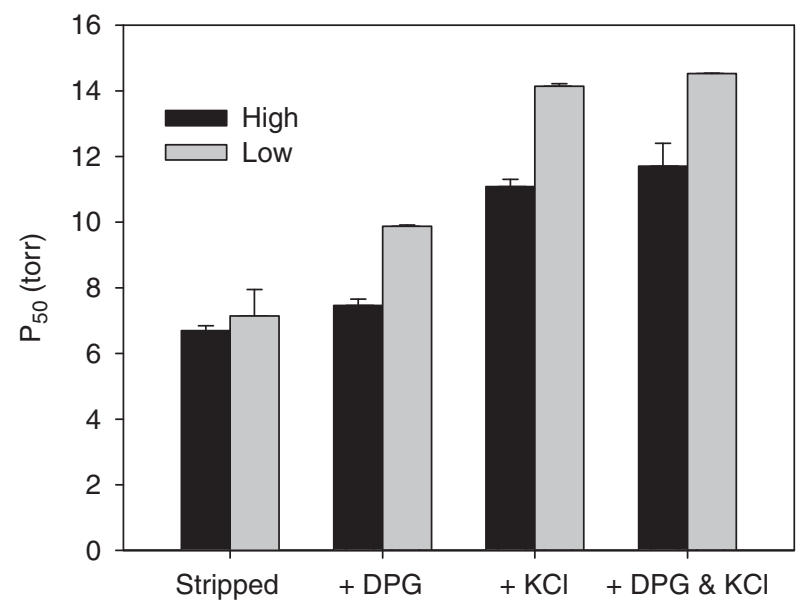

Figure 2 Functional differences between high- and low-altitude deer mouse hemoglobin isoforms. $P_{50}$ represents the $\mathrm{pO}_{2}$ at which hemoglobin is $50 \%$ saturated, and lower $P_{50}$ values indicate higher oxygen affinity. High-altitude isoforms exhibit higher oxygen affinity than low-altitude isoforms (lower $\mathrm{P}_{50}$ values) in the presence of allosteric cofactors (2,3 DPG and $\mathrm{Cl}^{-}$ions), but oxygen affinities are similar in their absence. These results demonstrate that differences in oxygen affinity are because of differences in their sensitivity to these erythrocytic allosteric cofactors. Figure modified from data presented in Storz et al. (2009, 2010a). plateaus of central Asia and, remarkably, has been observed flying over the summit of Mt Everest $(8850 \mathrm{~m})$ during its fall migration to northeastern India (Swan, 1970). A number of physiological traits increase $\mathrm{O}_{2}$ uptake, circulation and diffusion to contribute to the remarkable physiological performance of bar-headed geese in hypoxic conditions (Petschow et al., 1977; Perutz, 1983; Jessen et al., 1991; Scott and Milsom, 2007; Scott et al., 2009a, b, 2011). Recently, Scott et al. (2011) reported variation in cytochrome $c$ oxidase (COX) enzyme kinetics between bar-headed geese and closely related lowland species. This alteration of mitochondrial energy metabolism should be beneficial at high elevations, and may be related to a single amino-acid substitution in subunit three of the mitochondrial cytochrome $c$ oxidase gene (COX3).

COX catalyzes the terminal reduction of $\mathrm{O}_{2}$ in OXPHOS, and consequently plays a major role in tissue $\mathrm{O}_{2}$ utilization and the production of damaging reactive $\mathrm{O}_{2}$ species. Scott et al. (2011) examined the kinetic properties of several cardiac metabolic enzymes and one, COX, exhibited striking differences between bar-headed geese and lowland congeners. COX of bar-headed geese exhibited a much lower maximum catalytic activity $\left(V_{\max }\right)$ and substrate affinity for reduced cytochrome $c\left(\operatorname{cytc}\left[\mathrm{Fe}^{2+}\right]\right)\left(K_{m}\right)$ (Figure 3$)$. What is the potential adaptive benefit of these altered enzyme kinetics in bar-headed geese? Reduced $\mathrm{O}_{2}$ supply to $\mathrm{COX}$ can cause an increase in reactive $\mathrm{O}_{2}$ species production at high elevation by shifting mitochondrial redox to a more reduced state (Aon et al., 2010). Because they require less $\mathrm{cytc}\left[\mathrm{Fe}^{2+}\right]$ to maintain maximal activities of $\mathrm{COX}$, barheaded geese are able to offset this increased potential for oxidative damage by maintaining a more oxidized electron transport chain.

Differences in enzyme kinetics can be because of a combination of the inherent kinetic properties of enzymes, differences in gene expression, protein translation or degradation. In this case, the unique

\section{a}

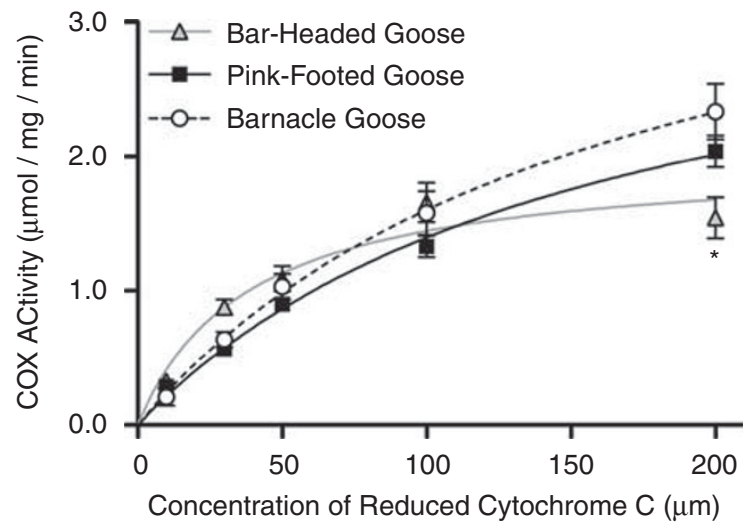

b
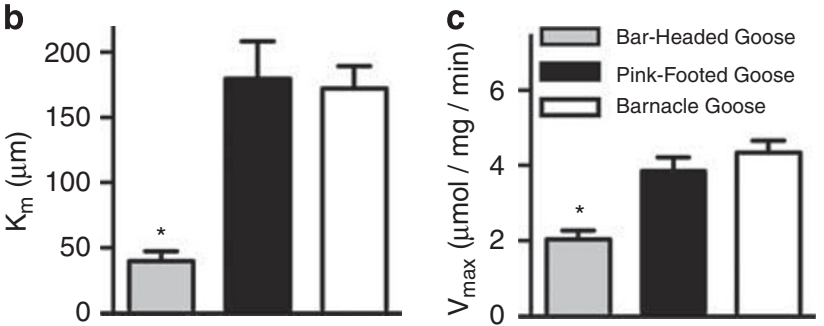

Figure 3 Cytochrome oxidase kinetics in bar-headed geese. Bar-headed geese differ from lowland congeners in (a) Michaelis-Menton enzyme kinetics, (b) substrate affinity $\left(K_{m}\right)$ and (c) maximal cytochrome oxidase activity $\left(V_{\max }\right)$. *Significant differences $(P<0.05)$ from both species of lowland geese. Figure modified from Scott et al. (2011). 
COX kinetics of bar-headed geese do not seem to be because of differences in mRNA or protein expression as expression differences were not uniquely different in bar-headed geese (Scott et al., 2011). Instead, analyses of sequence variation of subunit three of the mitochondrial COX gene (COX3) suggest that a single amino-acid substitution (Trp $116 \rightarrow \operatorname{Arg}$ ) may alter the interaction between subunits 1 (COX 1) and 3 (COX3) of the catalytic core of COX and this substitution likely contributes to the unique enzyme kinetics in barheaded geese. It is important to note that COX is a heteromeric enzyme that is composed of 10-12 subunits in birds (Kadenbach et al., 1991; Little et al., 2010). The authors only examined sequence variation in those subunits encoded by the mitochondrial genome (COX 1, 2 and 3), and hence it is still unknown whether sequence variation in nuclear-encoded COX subunits also contribute to the altered enzyme kinetics in bar-headed geese.

Although both these case studies are examples of candidate gene analyses, they illustrate the types of functional analyses that can be used to validate putatively adaptive loci. High-throughput genomic surveys are likely to identify scores of novel candidate genes for highaltitude adaptation over the coming years, but in order to make meaningful contributions to our understanding of the molecular mechanisms of adaptive traits, these candidates will need to be validated using lower-throughput functional assays. As a result, genomic studies of high-altitude adaptation are likely to provide fertile ground for collaborations between genomic biologists, population geneticists and biochemical physiologists.

\section{CONCLUSIONS}

High-altitude adaptation requires coordinated changes in the regulation and structure of many genes that interact in several biochemical pathways. To gain a more holistic understanding of high-altitude adaptation at the molecular level, the genomic scope of these types of studies needs to be expanded, and efforts should be made to integrate the study of DNA sequence polymorphism with analysis of transcriptional variation. Although genomic analyses will undoubtedly increase our understanding of the mechanisms of high-altitude adaptation and acclimatization, they are not without challenges of their own. One major challenge is being able to sufficiently interpret genomic patterns to make testable hypotheses of the functional consequences of underlying sequence variation. Even dense genome scans to identify loci that may have experienced a history of divergent selection often implicate large genomic regions ( 1-3 Mb; Sabeti et al., 2007) as candidate loci, and these regions often contain dozens to hundreds of genes, making it difficult to localize the actual target of natural selection. A second issue is related to experimental validation of candidate loci. Although genome scans are powerful analyses to identify novel candidates, the design of functional experiments to validate them could be hampered if the appropriate phenotype to be screened is not obvious. Pathway-level population genomic approaches expand the scope of genetic studies, and because they are hypothesis driven and focused on well-characterized pathways, the design of functional experiments may be more tractable. Finally, although genome-wide analyses of gene expression variation can provide insights into the role of regulatory variation in high-altitude adaptation, proper experimental designs are needed to separate the genetic and environmental components of transcriptional variation. Only heritable differences in gene expression can contribute to evolutionary adaptations. Plastic gene expression differences, however, are likely to underlie acclimatization responses, and documenting coordinated changes in gene regulation that are associated with exposure to high-altitude stressors can increase our understanding of the molecular mechanisms that underlie physiological adjustments at high altitude.

Finally, cold and hypoxia tend to operate synergistically to affect organism performance at high altitude (cold increases metabolic demands in the face of hypoxia), yet the vast majority of studies have focused solely on adaptation to hypoxia. Consideration of the joint effects of these co-varying environmental stressors should be a priority for future work (Altschuler and Dudley, 2006; Storz et al., 2010b).

\section{CONFLICT OF INTEREST}

The authors declare no conflict of interest.

\section{ACKNOWLEDGEMENTS}

Christian Biémont, Matt Carling, Christen Cheviron, Federico Hoffmann, Jürgen Gadau, Jay Storz and four anonymous reviewers made helpful comments on earlier versions of the manuscript, greatly improving it. Jay Storz and Graham Scott provided Figures 2 and 3, respectively. This work was supported by a grant from NSF (DEB-0841729) to RTB.

Aggarwal S, Negi S, Jha P, Singh P, Stobdan T, Pasha M et al. (2010). EGLN1 involvement in high-altitude adaptation revealed through genetic analysis of extreme constitution types defined in Ayurveda. Proc Natl Acad Sci USA 107: 18961-18966.

Altschuler DL, Dudley R (2006). Adaptations to life at high elevation: an introduction to the symposium. Integr Comp Biol 46: 3-4.

Andolfatto P, Prezeworski M (2000). A genome-wide departure from the standard neutral model in natural populations of Drosophila. Genetics 156: 257-268.

Aon MA, Cortassa S, O'Rourke B (2010). Redox-optimized ROS balance: a unifying hypothesis. Biochim Biophys Acta 1797: 865-877.

Bar-Or C, Czosnek H, Koltai H (2007). Cross-species microarray hybridizations: a developing tool for studying species diversity. Trends Genet 23: 200-207.

Baze M, Schlauch K, Hayes JP (2010). Gene expression of the liver in response to chronic hypoxia. Physiol Genomics 41: 275-288.

Beall C (2003). Adaptations to altitude: a current assessment. Annu Rev Anthropol 30: 423-456.

Beall C (2007). Two routes to functional adaptation: Tibetan and Andean high-altitude natives. Proc Natl Acad Sci USA 104: 8655-8660.

Beall C, Cavalleri G, Deng L, Elston R, Gao Y, Knight J et al. (2010). Natural selection on EPAS1 (HIF2alpha) associated with low hemoglobin concentration in Tibetan highlanders. Proc Natl Acad Sci USA 107: 11459-11464.

Beall CM, Bittenham GM, Strohl KP, Blagero J, Williams-Blagero S, Decker MJ (1998). Hemoglobin concentration of high-altitude Tibetans and Bolivian Amayra. Am J Phys Anthropol 106: 385-400.

Beaumont MA (2005). Adaptation and speciation: what can $\mathrm{F}_{\text {st }}$ tell us? Trends Ecol Evol 20: $435-440$.

Beaumont MA, Balding DJ (2004). Identifying adaptive genetic divergence among populations from genome scans. Mol Ecol 13: 969-980.

Beaumont MA, Nichols RA (1996). Evaluating loci for use in genetic analysis of population structure. Proc R Soc London B Biol Sci 263: 1619-1626.

Begun D, Aquadro C (1993). African and North American populations of Drosophila melanogaster are very different at the DNA level. Nature 365: 548-550.

Begun D, Aquadro C (1995). Evolution at the tip and base of the X chromosome in an African of Drosophila melanogaster. Mol Biol Evol 12: 382-390.

Bigham A, Bauchet M, Pinto D, Mao X, Akey J, Mei R et al. (2010). Identifying signatures of natural selection in Tibetan and Andean populations using dense genome scan data. PLoS Genet 6: e1001116.

Bigham A, Mao X, Mei R, Brusaert T, Wilson M, Julian C et al. (2009). Identifying positive selection candidate loci for high-altitude adaptation in Andean populations. Hum Genomics 4: 79-90.

Bouverot P (1985). Adaptation to Altitude-Hypoxia in Vertebrates. Springer-Verlag: Berlin. Chappell MA, Hayes JP, Snyder LRG (1988). Hemoglobin polymorphisms in deer mice (Peromyscus maniculatus), physiology of beta-globin variants and alpha-globin recombinants. Evolution 42: 681-688.

Chappell MA, Snyder LRG (1984). Biochemical and physiological correlates of deer mouse alpha-chain hemoglobin polymorphisms. Proc Natl Acad Sci USA 81: 5484-5488.

Charlesworth B (1998). Measures of divergence between populations and the effect of forces that reduce variability. Mol Biol Evol 15: 538-543.

Charlesworth B, Nordburg M, Charlesworth D (1997). The effects of local selection, balanced polymorphism and background selection on equilibrium patterns of genetic diversity in sub-divided populations. Genet Res 70: 155-174.

Chen WJ, Chen HW, Yu SL, Huang CH, Wang TD, Chen JJW et al. (2005). Geneexpressionprofiles in hypoxic preconditioning using cDNA microarray analysis: altered 
expression of an angiogenic factor, carcinoembryonic antigen-related cell adhesion molecule 1. Shock 24: 124-131.

Cheviron ZA, Brumfield RT (2009). Migration-selection balance and local adaptation of mitochondrial haplotypes in rufous-collared sparrows (Zonotrichia capensis) along an elevational gradient. Evolution 63: 1593-1605.

Cheviron ZA, Whitehead A, Brumfield RT (2008). Transcriptomic variation and plasticity in rufous-collared sparrows (Zonotrichia capensis) along an elevational gradient. $\mathrm{Mol}$ Ecol 17: 4556-4569.

Connes P, Yalcin O, Baskert O, Brun J, Hardeman M (2006). In health and in a normoxic environment, VO2 max is/is not limited primarily by cardiac output and locomotor muscle blood flow. J Appl Physiol 100: 2099.

Cork J, Purugganan M (2004). The evolution of molecular genetic pathways and networks. Bioessays 26: 479-484.

da Fonseca RR, Johnson WE, O'Brien SJ, Ramos MJ, Antunes A (2008). The adaptive evolution of the mammalian mitochondrial genome. BMC Genomics 9: 119.

Di Rocco F, Parisi G, Zambelli A, Vida-Rioja L (2006). Rapid evolution of cytochrome c oxidase subunit II camelids (Tylopoda, Camelidae). J Bioenerg Biomembr 38. 293-297.

Ekblom B, Bergland B (1991). Effect of erythopoietin administration on mammal aerobic power. Scand J Med Sci Sports 1: 88-93.

Ekblom B, Hermansen L (1968). Cardiac output in athletes. J Appl Physiol 25: 619-625.

Fan CH, lacobas DA, Zhou D, Chen QF, Lai JK, Gavrialov O et al. (2005). Gene expression and phenotypic characterization of mouse heart after chronic constant or intermittent hypoxia. Physiol Genomics 22: 292-307.

Fay J, Wu C (2000). Hitchhiking under positive Darwinian selection. Genetics 155: 1405-1413.

Flowers J, Sezgin E, Kumagai S, Duvernell D, Matzkin L, Schmidt P et al. (2007). Adaptive evolution of metabolic pathways in Drosophila. Mol Biol Evol 24: 1347-1354.

Fontanillas P, Depraz A, Giorgi MS, Perrin NR (2005). Nonshivering thermogenesis capacity associated with mitochondrial DNA haplotypes in the greater white-toothed shrew, Crocidura russula. Mol Ecol 14: 661-670.

Gracey AY, Chaney ML, Boomhower JP, Tyburczy WR, Connor K, Somero GN (2008). Rhythms of gene expression in a fluctuating intertidal environment. Curr Biol 18: 1-7.

Gracey AY, Fraser EJ, Li W, Fang Y, Taylor RR, Rogers J et al. (2004). Coping with cold: An integrative, multitissue analysis of the transcriptome of a poikilothermic vertebrate. Proc Natl Acad Sci USA 101: 16970-16975.

Gracey AY, Troll J, Somero GN (2001). Hypoxia-induced expression profiling in the euryoxic fish Gillichthys mirabilis. Proc Natl Acad Sci USA 94: 1993-1998.

Guyton A, Richardson T (1961). Effect of hematocrit on venous return. Circ Res 9: 157-164.

Hall E (1981). The Mammals of North America, Volume II. Blackburn Press: Caldwell, NJ. Hassanin A, Ropiquet A, Couloux A, Cruaud C (2009). Evolution of the mitochondrial genome in mammals living at high altitude: new insights from a study of the tribe Caprini (Bovidae Antilopinae). J Mol Evol 68: 293-310.

Hochachka P (1998). Mechanism and evolution of hypoxia tolerance in humans. J Exp Biol 201: 1243-1254.

Hochachka P, Somero G (2002). Biochemical Adaptation: Mechanism and Process in Physiological Evolution. Oxford University Press: Oxford.

Hodges E, Xuan Z, Balija V, Kramer M, Molla M, Smith S et al. (2007). Genome-wide in situ exon capture for selective resequencing. Nat Rev Genet 39: 1522-1527.

Hudson R, Kaplan N (1995). Deleterious background selection with recombination. Genetics 141: 1605-1617.

Innan H (2006). Modified Hudson-Kreitman-Aguade test and two-dimensional evaluations of neutrality tests. Genetics 173: 1725-1733.

Jaakkola P, Mole D, Tiam Y-M, Wilson M, Gielbert J, Gaskell S et al. (2001). Targeting of HIF-alpha to the von Hippel-Lindau ubiquitylation complex by O2-regulated prolyl hydroxylation. Science 20: 468-472.

Jessen J, Wong A, Aquadro C (2007). Approaches for identifying targets of positive selection. Trends Genet 23: 568-577.

Jessen TH, Weber RE, Fermi G, Tame J, Braunitzer G (1991). Adaptation of bird hemoglobins to high altitudes: demonstration of molecular mechanism by protein engineering. Proc Natl Acad Sci USA 88: 6519-6522.

Julian C, Wilson M, Lopez M, Yamashiro H, Tellez W, Rodriguez A et al. (2009). Augmented uterine artery blood flow and oxygen delivery protect Andeans from altitude-associated reductions in fetal growth. Am J Physiol Regul Integr Comp Physiol 296: R1564-R1575.

Kadenbach B, Stroh A, Hüther FJ, Reimann A, Steverding D (1991). Evolutionary aspects of cytochrome c oxidase. J Bioenerg Biomembr 23: 321-334.

Kanstrup I, Ekblom B (1984). Blood volume and hemoglobin concentration as determinants of maximal aerobic power. Med Sci Sports Exerc 16: 256-262.

Kaplan N, Hudson R, Langley C (1998). The 'hitchhiking effect' revisited. Genetics 123 : 887-899.

Kim Y, Nielsen R (2004). Linkage disequilibrium as a signature of selective sweeps. Genetics 167: 1513-1524.

Kim Y, Stephan W (2002). Detecting a local signature of genetic hitchhiking along a recombining chromosome. Genetics 160: 765-777.

Lewontin RC, Krakauer J (1973). Distribution of gene frequency as a test of the theory of the selective neutrality of polymorphisms. Genetics 74: 175-195.

Little AG, Kocha KM, Lougheed SC, Moyes CD (2010). Evolution of the nuclear-encoded cytochrome oxidase subunits in vertebrates. Physiol Genomics 42: 76-84.

Lorenzo V, Yang Y, Simonson T, Nussenzveig R, Jorde L, Prchal J et al. (2009). Genetic adaptation to extreme hypoxia: study of high-altitude pulmonary edema in a threegeneration Han Chinese family. Blood Cells Mol Dis 43: 221-225.
Lorkowski S, Cullen PM (eds). (2006). Analyzing Gene Expression, A Handbook of Methods: Possibilities and Pitfalls. Wiley-VCH: Weinheim, pp 954.

Luo Y, Gao W, Gao Y, Tang S, Huang Q, Tan X et al. (2008). Mitochondrial genome analysis of Ochotona cruzoniae and implication of cytochrome $\mathrm{c}$ oxidase in hypoxic adaptation. Mitochondrion 8: 352-357.

Lutz P (1980). On oxygen affinity of bird blood. Am Zool 20: 187-198.

Marguerat S, Bähler J (2009). RNA-seq: from technology to biology. Cell Mol Life Sci 67: 569-579.

Maynard-Smith J, Haigh J (1974). The hitch-hiking effect of a favourable gene. Genet Res 23: 23-25.

McVean G (2007). The structure of linkage disequilibrium around a selective sweep. Genetics 175: 1395-1406.

Monge C, Leon-Velarde F (1991). Physiological adaptation to high-altitude: oxygen transport in mammals and birds. Physiol Rev 71: 1135-1172.

Moore LG, Niermeyer S, Zamudio S (1998). Human adaptation to high altitude: regional and life-cycle perspectives. Am J Phys Anthropol 41: 25-64.

Moore LG, Regensteiner JG (1983). Adaptation to high-altitude. Annu Rev Anthropol 12: 285-304.

Neilsen R (2001). Statistical tests of selective neutrality in the age of genomics. Heredity 86: 641-647.

Neilsen R (2005). Molecular signatures of natural selection. Annu Rev Genet 39: 197-218.

$\mathrm{Ng}$ SB, Turner EH, Robertson PD, Flygare S, Bingham A, Lee C et al. (2009). Targeted capture and massively parallel sequencing of 12 human exomes. Nature 461: 272-276

Novembre J, Di Rienzo A (2009). Spatial patterns of variation due to natural selection in humans. Nat Rev Genet 10: 745-755.

Okou D, Meltz Steinberg K, Middle C, Cutler D, Albert T, Zwick M (2007). Microarray-based genomic selection for high throughput resequencing. Nat Methods 4: 903-905.

Perutz MF (1983). Species adaptation in a protein molecule. Mol Biol Evol 1: 1-28.

Petschow D, Wurdinger I, Baumann R, Duhm J, Braunitzer G, Bauer C (1977). Causes of high blood $\mathrm{O}_{2}$ affinity of animals living at high altitude. J App/ Physiol 42: 139-143.

Powell FL (2003). Functional genomics and the comparative physiology of hypoxia. Annu Rev Physiol 65: 203-230.

Rankin E, Biju M, Liu Q, Unger T, Rha J, Johnson R et al. (2007). Hypoxia-inducible factor2 (HIF2) regulates hepatic erythropoietin in vivo. J Clin Invest 117: 1068-1077.

Sabeti P, Reich D, Higgins J, Levine H, Richter D, Schaffner S et al. (2002). Detecting recent positive selection in the human genome from haplotype structure. Nature 419: 832-837.

Sabeti P, Varilly P, Fry B, Lohmuelller J, Hostetter E, Costsapas C et al. (2007). Genomewide detection and characterization of positive selection in human populations. Nature 449: 913-918.

Scott GR, Milsom WK (2006). Flying high: a theoretical analysis of the factors limiting exercise performance in birds at altitude. Respir Physiol Neurobiol 154: 284-301.

Scott GR, Milsom WK (2007). Control of breathing and adaptation to high altitude in the bar-headed goose. Am J Physiol Regul Integr Comp Physiol 293: R379-R391.

Scott GR, Egginton S, Richards JG, Milsom WK (2009a). Evolution of muscle phenotype for extreme high altitude flight in the bar-headed goose. Proc $R$ Soc B Biol Sci 276: 3645-3653.

Scott GR, Richards JG, Milsom WK (2009b). Control of respiration in flight muscle from the high altitude bar-headed goose and low altitude birds. Am J Physiol Regul Integr Comp Physiol 297: R1066-R1074.

Scott GR, Schulte PM, Egginton S, Scott ALM, Richards JG, Milsom WK (2011). Molecular evolution of cytochrome $\mathrm{c}$ oxidase underlies high-altitude adaptation in the bar-headed goose. Mol Biol Evol 28: 351-363.

Semenza GL (2009). Oxygen homeostasis. WIREs Syst Biol Med 2: 336-361.

Shaw R (2006). Glucose metabolism and cancer. Curr Opin Cell Biol 18: 598-608.

Simonson T, Yang Y, Huff C, Yun H, Qin G, Witherspoon D et al. (2010). Genetic evidence for high-altitude adaptation in Tibet. Science 329: 72-75.

Snyder LRG (1978). Genetics of hemoglobin in the deer mouse, Peromyscus maniculatus. I. Genetics 89: 511-530.

Snyder LRG (1985). Low $P_{50}$ in deer mice native to high altitude. J Appl Physiol 58: 193-199.

Snyder LRG, Born S, Lechner AJ (1982). Blood oxygen affinity in high- and low-altitude populations of the deer mouse. Respir Physiol 48: 89-105.

Snyder LRG, Hayes JP, Chappell MA (1988). Alpha-chain hemoglobin polymorphisms are correlated with altitude in the deer mouse, Peromyscus maniculatus. Evolution 42 : 689-697.

Somero GN (2005). Linking biogeography to physiology: evolutionary and acclimatory adjustments of thermal limits. Front Zool 2: 1-9.

Stephan W, Song Y, Langley C (2006). The hitchhiking effect on linkage disequilibrium between linked neutral loci. Genetics 172: 2647-2663.

Stephan W, Wiehe T, Lenz M (1992). The effect of strongly selected substitutions on neutral polymorphism: analytical results based on diffusion theory. Theor Popul Biol 41: 237-254.

Storz JF (2005). Using genome scans of DNA polymorphism to infer adaptive population divergence. Mol Ecol 14: 671-688.

Storz JF (2010). Genes for high altitude. Science 329: 40-41.

Storz JF, Cheviron ZA (2011). Genomic and transcriptomic approaches to the study of highaltitude adaptation. Adv Exp Med Biol (in press).

Storz JF, Kelly J (2008). Effects of spatially varying selection on nucleotide variation and linkage disequilibrium: insights from deer mouse globin genes. Genetics 180: 367-379. 
Storz JF, Moriyama H (2008). Mechanisms of hemoglobin adaptation to high-altitude hypoxia. High Alt Med Biol 9: 148-157.

Storz JF, Runck A, Moriyama H, Weber RE, Fago A (2010a). Genetic differences in hemoglobin function between highland and lowland deer mice. J Exp Biol 213: 2565-2574.

Storz JF, Runck A, Sabatino S, Kelly J, Ferrand N, Moriyama H et al. (2009). Evolutionary and functional insights in the mechanism underlying high-altitude adaptation of deer mouse hemoglobin. Proc Natl Acad Sci USA 106: 14450-14455.

Storz JF, Sabatino SJ, Hoffman FG, Gering EJ, Moriyama H, Ferrand N et al. (2007). The molecular basis of high-altitude adaptation in deer mice. PLoS Genet 3: 448-458.

Storz JF, Scott GR, Cheviron ZA (2010b). Phenotypic plasticity and genetic adaptation to high-altitude hypoxia in vertebrates. J Exp Biol 213: 4125-4136.

Storz JF, Wheat C (2010). Integrating evolutionary and functional approaches to infer adaptation at specific loci. Evolution 64: 2489-2509.

Swan L (1970). Goose of the Himalayas. Nat Hist 70: 68-75.

Teshima K, Coop G, Prezworski M (2006). How reliable are empirical genome scans for selective sweeps. Genome Res 16: 702-712.

Villafuerte F, Cardenas R, Monge C (2004). Optimal hemoglobin concentration and high altitude: a theoretical approach for Andean men at rest. J Appl Physiol 96: $1581-1588$

Wagner A (2009). Evolutionary constraints permeate large metabolic networks. BMC Evol Biol 9: 231.
Wang G, Jiang B, Rue E, Semenza G (1995). Hypoxia-inducible factor 1 is a basic-helixloop-helix-PAS heterodimer regulated by cellular $\mathrm{O}_{2}$ tension. Proc Natl Acad Sci USA 92: $5510-5514$

Wang Z, Gerstein M, Snyder M (2009). RNA-Seq: a revolutionary tool for transcriptomics. Nat Rev Genet 10: 57-63.

Weber RE (2007). High-altitude adaptation in vertebrate hemoglobins. Respir Physio Neurobiol 158: 132-142.

Weber RE, Fago A (2004). Functional adaptation and its molecular basis in vertebrate hemoglobins, neuroglobins and cytoglobins. Respir Physiol Neurobiol 144: 141-159.

Weber RE, Ostojic H, Fago A, Dewilde S, Van Hauwaert ML, Moens L et al. (2002). Novel mechanism for high-altitude adaptation in hemoglobin of the Andean frog Telmatobius peruvianus. Am J Physiol Regul Integr Comp Physiol 283: R1052-R1060.

Whitehead A, Crawford DL (2006). Variation within and among species in gene expression: raw material for evolution. $\mathrm{Mol} \mathrm{ECO}$ 15: 1197-1211.

Wilding J, Gause-Nilsson I, Persson A (2007). Tesaglitazar, as add-on therapy to sulphonylurea, dose-dependently improves glucose and lipid abnormalities in patients with type 2 diabetes. Diab Vasc Dis Res 4: 194-203.

Xu S, Luosang J, Hua S, He J, Ciren A, Wang W et al. (2007). High altitude adaptation and phylogenetic analysis of Tibetan horse based on the mitochondrial genome. $J$ Genet Genomics 34: 720-729.

Yi X, Liang Y, Huerta-Sanchez E, Jin X, Cuo Z, Pool J et al. (2010). Sequencing 50 human exomes reveals adaptation to high altitude. Science 329: 75-78. 